\title{
Diversity, Distribution, and Evolution of Solanum bulbocastanum Late Blight Resistance Genes
}

\author{
Anoma A. Lokossou, ${ }^{1}$ Hendrik Rietman, ${ }^{1}$ Miqia Wang, ${ }^{1}$ Pavel Krenek, ${ }^{1,2}$ Hanneke van der Schoot, ${ }^{1}$ \\ Betty Henken, ${ }^{1}$ Roel Hoekstra, ${ }^{3}$ Vivianne G. A. A. Vleeshouwers, ${ }^{1}$ Edwin A. G. van der Vossen, ${ }^{1}$ \\ Richard G. F. Visser, ${ }^{1}$ Evert Jacobsen, ${ }^{1}$ and Ben Vosman ${ }^{1}$ \\ ${ }^{1}$ Wageningen UR Plant Breeding, P.O. Box 16, 6700AA, Wageningen, The Netherlands; ${ }^{2}$ Department of Transgenic Models \\ of Diseases, Institute of Molecular Genetics AS CR, v. v. i., Videnska 1083, CZ-142 20 Prague 4, Czech Republic; ${ }^{3}$ Centre \\ for Genetic Resources the Netherlands (CGN), Wageningen University and Research Centre (WUR), P.O. Box 16, 6700 AA \\ Wageningen, The Netherlands
}

Submitted 18 January 2010. Accepted 5 May 2010.

\begin{abstract}
Knowledge on the evolution and distribution of late blight resistance genes is important for a better understanding of the dynamics of these genes in nature. We analyzed the presence and allelic diversity of the late blight resistance genes Rpi-blb1, Rpi-blb2, and Rpi-blb3, originating from Solanum bulbocastanum, in a set of tuber-bearing Solanum species comprising 196 different taxa. The three genes were only present in some Mexican diploid as well as polyploid species closely related to $S$. bulbocastanum. Sequence analysis of the fragments obtained from the Rpi-blb1 and Rpiblb3 genes suggests an evolution through recombinations and point mutations. For Rpi-blb2, only sequences identical to the cloned gene were found in $S$. bulbocastanum accessions, suggesting that it has emerged recently. The three resistance genes occurred in different combinations and frequencies in $S$. bulbocastanum accessions and their spread is confined to Central America. A selected set of genotypes was tested for their response to the avirulence effectors IPIO-2, Avr-blb2, and Pi-Avr2, which interact with Rpi-blb1, Rpi-blb2, and Rpi-blb3, respectively, as well as by disease assays with a diverse set of isolates. Using this approach, some accessions could be identified that contain novel, as yet unknown, late blight resistance factors in addition to the Rpi-blb1, Rpi-blb2, and Rpi-blb3 genes.
\end{abstract}

Solanum bulbocastanum is well known for its resistance to late blight (Niederhauser and Mills 1953), a disease caused by the oomycete Phytophthora infestans. The species belongs to the section Petota of the genus Solanum. It is a diploid, selfincompatible species native to Central America. It inhabits mountainous areas at an altitude between 1,200 and 2,300 m (Spooner et al. 2004) from northwestern Mexico (Durango and Nayarit regions) all the way south to Honduras.

Although characterized by late blight resistance, S. bulbocastanum resistance sources have not been widely exploited

Current address for M. Wang: Bayer CropScience (China) Company Ltd., 34/F Jing Guang Center, Hu Jia Lou, Chaoyang District, Beijing 100029, China.

Current address for E. A. G. van der Vossen: Keygene N.V., Agro Business Park 90, 6708 PW Wageningen, The Netherlands.

Corresponding author: Ben Vosman; E-mail: ben.vosman@wur.nl

* The $\boldsymbol{e}$-Xtra logo stands for "electronic extra" and indicates that four supplementary tables and one supplementary figure are published online. yet, which is mainly due to crossing barriers with cultivated potato (Hermsen and Ramanna 1973; Helgeson et al. 1998). Until now, four different nucleotide-binding site leucine-rich repeat resistance genes have been identified in and cloned from S. bulbocastanum: namely, Rpi-blbl (van der Vossen et al. 2003), also known as $R B$ (Song et al. 2003); Rpi-blb2 (van der Vossen et al. 2005); Rpi-blb3 (Lokossou et al. 2009); and Rpi-bt1 (Oosumi et al. 2009), which opens the possibility to study the distribution and diversity of these genes in the section Petota.

The distribution of specific resistance genes in natural populations has been studied in a few cases only: Rps 2 and Rpp13 in Arabidopsis thaliana (Mauricio et al. 2003; Rose et al. 2004), $C f-4$ and $C f-9$ in tomato (Kruijt et al. 2005; Caicedo 2008), as well as Pm3 (Bhullar et al. 2009; Yahiaoui et al. 2009) and Lr21 (Huang et al. 2009) from wheat. Mauricio and associates (2003) studied the diversity of Rps2, a resistance gene against the bacteria Pseudomonas syringae, in a worldwide sample of 27 A. thaliana accessions. They favored balancing selection as the explanation for the Rps 2 variation. This maintenance of variance by natural selection might be a general feature for the dynamics of resistance $(R)$ gene evolution (Ellis et al. 1999; Luck et al. 2000). From the study on diversity for Rpp13, a resistance gene in A. thaliana against Hyaloperonospora arabidopsis, which is characterized by an extreme sequence diversity and resistance to various pathogen isolates, the suggestion was made that the co-evolutionary interaction between host and pathogen must be very active (Rose et al. 2004). Confirmation was provided with the analysis of the recently identified avirulence (Avr) gene of Rppl3, Atr13, which reveals high sequence diversity for this effector as well (Allen et al. 2008); moreover, one Rppl3 allele seems to recognize another H. arabidopsis effector (Hall et al. 2009). Kruijt and associates (2005) showed that a high proportion of wild tomato plants specifically recognize the Cladosporium fulvum Avr4 and Avr9 elicitors, and functional homologs of the $C$. fulvum resistance genes $C f-4$ and $C f-9$ are conserved in diverged tomato species. The $C f-4$ and $C f-9$ genes appear to have been maintained by selection pressure imposed by the pathogen C. fulvum. Caicedo (2008) studied the distribution of $C f-2$ homologs in natural populations of $S$. pimpinellifolium and deduced that, primarily, the geographic distribution of $C f$ 2 homolog diversity has been shaped by demographic factors or by selective pressure with a clinal geographic distribution. Levels of homologue diversity varied greatly between populations. Huang and associates (2009) investigated the origin of 
the leaf rust resistance gene $L r 21$ that has been introgressed into hexaploid wheat from Aegilops tauschii by functional screens and sequence analysis. The $L r 21$ gene was found in only12 accessions out of the 528 accessions representing the geographic diversity of the goatgrass Aegilops tauschii. All 12 had identical sequences and had been collected within a small area along the Caspian sea in Iran and Azerbaijan. Bhullar and associates (2009) investigated the distribution of the Pm3 gene, which confers resistance to the powdery mildew fungus in wheat, in a selected set of 1,320 bread wheat landraces. Additionally, Yahiaoui and associates (2009) showed that the Pm3 sequence diversity was higher in wild emmer wheat from the Levant area compared with the accessions from Turkey.

As population genetic processes and dynamics might affect the evolution of $R$ genes, a better understanding of variation within and between populations is crucial. Spooner and associates (2009) evaluated several factors that might be predictive for identifying pest- and disease-resistant plants in wild relatives of the cultivated potato. For late blight resistance, they identified taxonomic, climatic, and geographic (latitude and altitude) variables. From these analyses, it was clear that species level was the best predictor for resistance against Phytophthora infestans. These results stressed the need to use more focused evaluations of germplasm and to have a clear picture of geographical patterns of diversity in late blight resistance genes in wild Solanum species. To analyze these, here, use has been made of well-studied $R$ genes such as Rpi-blb1, Rpi-blb2, and Rpi-blb3, which are excellent candidates because both $A v r$ and $R$ genes have been identified and cloned.

The Rpi-blbl gene is located on linkage group VIII near marker CT64 in a cluster of four resistance gene analogues (RGA) (van der Vossen et al. 2003). Its susceptible haplotype, rb, is characterized by an 18-bp deletion (Song et al. 2003). In an evaluation by Wang and associates (2008) using 44 species of Solanum section Petota for Rpi-blbl (RGA2) and its flanking $R G A$ (RGAl and RGA3), it was shown that the genes had a different distribution and diversity. The flanking $R G A l$ appeared to be highly conserved within the tuber-bearing Petota and was also found in the non-tuber-bearing species of the section, while $R G A 3$ was only present in some tuber-bearing species. The Rpi-blbl gene was found in Mexican diploid species (S. bulbocastanum and $S$. cardiophyllum) and the Mexican polyploid species $S$. stoloniferum (including $S$. papita and S. polytrichon) (Wang et al. 2008). Functional analysis of the genes found in S. stoloniferum (Rpi-stol and Rpi-ptal) indeed confirmed the functional homology with Rpi-blbl (Vleeshouwers et al. 2008). The occurrence of Rpi-blbl homologues in S. stoloniferum was suggested to be the result of common ancestry (e.g., S. bulbocastanum was suggested as one of the parents of the allopolyploid S. stoloniferum) (Wang et al. 2008).

Rpi-blb2 is located on linkage group VI near marker CT119, in a locus harboring at least $15 \mathrm{Mi}-1$ gene homologues (van der Vossen et al. 2005). The Mi-l gene of tomato confers resis tance to the root-knot nematode Meloidogyne incognita (Milligan et al. 1998) and shares $82 \%$ overall protein sequence identity with Rpi-blb2 (van der Vossen et al. 2005). Rpi-verl, a late blight $R$ gene from $S$. verrucosum, also maps in this region (Jacobs et al. 2010). Other $R$ genes found at this locus in to mato include $\mathrm{Ol}-\mathrm{I}$ and $O l-3$ (Bai et al. 2005) and $C f 2$ and $C f 5$ (Dickinson et al. 1993), conferring resistance to Oidium neoly copersici and $C$. fulvum, respectively. Apart from $S$. bulbocas tanum, no other species were found to contain Rpi-blb2 (Wang et al. 2008).

Rpi-blb3 is located on linkage group IV near marker TG339 in a major late blight resistance gene cluster containing $R 2$, Rpi-abpt, and R2-like (Park et al. 2005). Late blight resistances with a more quantitative trait locus (QTL)-like appearance such as those of S. microdontum (Sandbrink et al. 2000; Tan et al. 2008) and those found in tomato (Brouwer et al. 2004) map into the same region. Tan and associates (2008) proposed that the QTL from $S$. microdontum, indentified as Rpi-mcdl, is a major $R$ gene. Other $R$ genes, mapping to the same region, include $N y_{t b r}$, conferring resistance to Potato virus $Y$ (CelebiToprak et al. 2002), and the Hero resistance gene which confers resistance to all known pathotypes of Globodera rostochiensis and partial resistance to G. pallida (Ernst et al. 2002). Allele mining studies for Rpi-blb3 are not yet reported.

Distribution of $R$ genes in natural populations is not easy to study phenotypically, as resistance to a particular pathogen might result from the presence of one or more different $R$ genes, which is the case for populations of $S$. bulbocastanum. One approach could be to use Avr genes to determine whether a corresponding $R$ gene is present; in our case, Avrblb1, which interacts with Rpi-blb1 (Vleeshouwers et al. 2008); Avrblb2, interacting with Rpi-blb2 (Oh et al. 2009); and Pi-Avr2, interacting with Rpi-blb3 (Lokossou et al. 2009). However, the Rpiblb3 gene has several close relatives, all recognizing the same set of Avr genes (Lokossou et al. 2009). Also, carrying out such analysis in a large number of different species is not straight forward. Studying the distribution of $R$ genes with highly specific molecular markers and deduction of the phenotype for positive genotypes is an alternative. However, one has to keep in mind that the functionality of $R$ genes might be changed by one single-nucleotide polymorphism (SNP) or by insertions or deletions. A combination of the two approaches and screening with key $P$. infestans isolates seems to be a beneficial strategy that will allow the identification of other resistance genes toward this devastating disease.

In this article, we studied the allelic frequencies of the Rpiblb1, Rpi-blb2, and Rpi-blb3 genes in several wild tuber-bearing Solanum accessions by performing allele mining with $R$ gene-specific primers. Additionally, Avr expression assays as well as detached leaf assays with key $P$. infestans isolates were used to strengthen the evidence for the presence of functional alleles. We relate the occurrence of the genes to the geographical origin of the accessions.

\section{RESULTS}

\section{Screening of Solanum section Petota} for the presence of $\mathrm{Rpi}$-blb resistance genes.

In total, 196 different taxa from Solanum section Petota were screened for the presence of the Rpi-blbl and Rpi-blb3 genes. The presence of Rpi-blb2 was not assessed in this wide set of taxa because a previous study had already shown that the distribution of this gene was confined to $S$. bulbocastanum (Wang et al. 2008). We used the plant material described by Jacobs and associates (2008) and, as far as available, at least five accessions from each species and five individuals per accession (in total, 4,929 genotypes). One screen was carried out with the $1 / 1^{\prime}$ primer pair, which is specific for the functional allele of Rpi-blb1 (Colton et al. 2006). Polymerase chain reaction (PCR) fragments were detected in S. bulbocastanum, $S$. cardiophyllum subsp. cardiophyllum, and S. stoloniferum (sensu Spooner et al. 2004) only.

The collection was also screened with primers specific for Rpi-blb3, and six species were found to contain putative Rpiblb3 homologues: S. pinnatisectum, S. bulbocastanum (including some subspecies), S. hjertingii, S. nayaritense, S. brachistotrichum, and S. stoloniferum.

\section{Detailed investigation}

of $S$. bulbocastanum and related species.

An additional 72 accessions originating from Mexico and Guatemala of the series Bulbocastana, Pinnatisecta, and Longi- 
pedicellata was evaluated for the presence of Rpi-blbl, Rpiblb2, and Rpi-blb3 genes. For 63 accessions, precise coordinates (longitude and latitude data) were available, pointing to 52 different locations (Supplementary Table S1).

The presence or absence of Rpi-blbl was analyzed using the primer combinations Blb1 F/R, detecting the Rpi-blbl locus (Wang et al. 2008), and Blb 1/1' (Colton et al. 2006). The RGA1 F/R primer pair served as a positive control for DNA quality as this gene is present in all tuber-bearing Solanaceae tested (Wang et al. 2008).

The primer pair Blb1 F/R amplified fragments of the expected size in 27 out of the $36 \mathrm{~S}$. bulbocastanum accessions, the $S$. brachistotrichum accession, both $S$. cardiophyllum accessions, and four out of nine $S$. stoloniferum accessions. The primer pair Blb 1/1' amplified fragments in a total of 29 accessions from 23 different locations and composed of 23 of the 36 accessions of $S$. bulbocastanum, both $S$. cardiophyllum accessions, and four of nine $S$. stoloniferum (Fig. 1A).

The primer pair Blb2F/R (Wang et al. 2008) amplified Rpiblb2 in seven of the 36 accessions of $S$. bulbocastanum and in both $S$. cardiophyllum accessions. The positive accessions originated from six different locations (Fig. 1A).

The primers specific for Rpi-blb3 amplified distinct fragments in 35 accessions from 28 different locations. Accessions showing amplification originated from 26 of the $36 \mathrm{~S}$. bulbocastanum accessions, both $S$. pinnatissectum accessions, the $S$. brachistotrichum accession, one of the two $S$. cardiophyllum accessions, three of the four $S$. hjertingii accessions, and two of the nine $S$. stoloniferum accessions (Fig. 1A).

The Rpi-blb1 and Rpi-blb3 gene combinations were found in genotypes from $14 S$. bulbocastanum accessions originating from 12 different locations. The Rpi-blb1 and Rpi-blb2 genes were found together in genotypes from five $S$. bulbocastanum accessions from two different locations. The Rpi-blb2 and Rpi- blb3 fragments were found together in two $S$. bulbocastanum accessions from two distinct locations (Fig. 1B).

The percentages of the individual genotypes of $S$. bulbocastanum containing Rpi-blb1, Rpi-blb2, or Rpi-blb3 fragments were 36,9 , and $56 \%$, respectively.

Three genotypes, belonging to PI498223 and PI545711 accessions, harbored all three genes. In only a small number of accessions, all genotypes harbored the same gene; in two accessions, all genotypes tested contained Rpi-blbl; and, from 10 accessions, all genotypes tested contained Rpi-blb3. Interestingly, $91 \%$ of the genotypes from the subspecies $S$. bulbocastanum subsp. partitum contained Rpi-blb3.

\section{Allelic variation}

in the Rpi-blb1, Rpi-blb2, and Rpi-blb3 gene fragments.

To verify the nature of the amplified fragments and to explore the $R$-gene diversity at the nucleotide level, part of the gene was sequenced for all the positives accessions. The results are presented in Tables 1 through 3.

The Rpi-blbl-amplified sequence spans 1,734 bp in total, composed of two separate parts: the first part is from the start codon to position 545, obtained with primer pair 517/1519. The second part is from position 2,404 to the stop codon obtained with primer pairs Blb1F/R, 1531/519, and 1/1'. Sequence alignment revealed a total of 56 SNP compared with the cloned Rpi-blbl gene with 34 SNP in the coding region, four SNP in an intron part, and the deletion of 18 nucleotides, which is characteristic for the Rpi-blbl nonfunctional allele also known as $r b$ (Song et al. 2003; Colton et al. 2006). In all, 47\% of the SNP resulted in nonsynonymous amino acid changes.

The 34 haplotypes could be classified into 13 groups (A to M) based on the identity of the nonsynonymous SNP changes (Table 1). Each haplotype group contained one to 18 accessions. Group A, which is the dominant group, contains haplo-

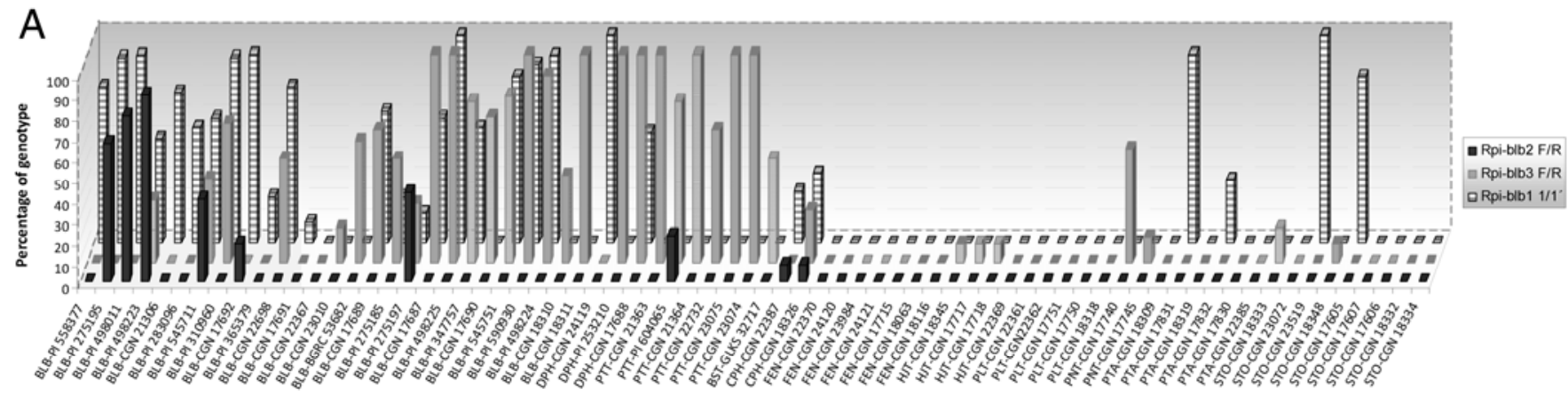

Accessions

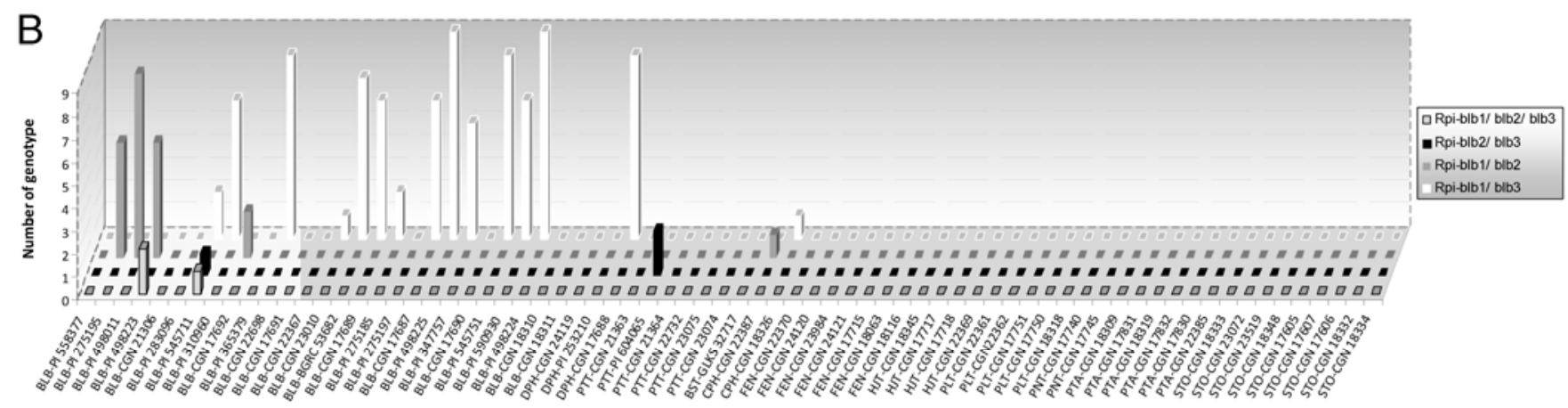

Accessions

Fig. 1. Rpi-blb1, Rpi-blb2, and Rpi-blb3 presence in Solanum bulbocastanum and related species. A, Percentage of genotypes per accession containing Rpi-blb genes fragments. B, Number of genotypes per accession containing combinations of Rpi-blb genes fragments. Abbreviations: BLB, S. bulbocastanum; BST, S. brachistotrichum; CPH, S. cardiophyllum; DPH, S. bulbocastanum subsp. dolichophyllum; FEN, S. fendleri; HJT, S. hjertingii; PLT, S. polytrichon; PNT, S. pinnatissectum; PTA, S. papita; PTT, S. bulbocastanum subsp. partitum; STO, S. stoloniferum. 
types without nonsynonymous SNP and is only composed of $S$. bulbocastanum accessions with a sequence identical to the cloned Rpi-blbl gene. Group B additionally contains S. stoloniferum (Rpi-stol like) haplotypes while $S$. papita and $S$. polytrichon (Rpi-ptal and Rpi-plt1 like) are part of group C. Haplotypes C2, A11, C6, E2, I1, and L1 display double SNP which are probably the result of heterozygous genotypes. Haplotype M1 represents the known nonfunctional allele, identified by the 18-bp deletion (Song et al. 2003).

The Rpi-blb2 amplified sequence spans 715 bp from position 2,157 to 2,872, derived from the primers Blb2F/R (Wang et al. 2008). From the two sequences obtained, one is $100 \%$ identical to the Rpi-blb2 sequence and the second one displayed a variable region composed of a 72-nucleotide deletion at the beginning of the sequence followed by 26 SNP in the remaining part (Table 2). The Rpi-blb3-amplified sequence spans 618 bp from position 918 to 1,536. Sequence alignment reveals 33 SNP displayed in 22 haplotypes containing one to 16 accessions (Table 3). In all, 66\% of the SNP lead to nonsynonymous amino acid changes. Our classification differentiates five groups containing one to 34 accessions, according to the type of polymorphism present in the sequence. Group A displays one SNP per haplotype, A1 and A2 being the most commonly present in 12 and 16 accessions, respectively. Haplotypes A6 and A7 show a 1-nucleotide deletion leading to a frame shift. Group B haplotypes have four SNP in common clearly defining a polymorphic sequence block. The B haplotypes are exclusively identified in accessions originating from Guatemala (Supplementary Fig. 1). Haplotype B6 contains a SNP in position 1,396, resulting in a stop codon. Group C comprises haplotypes with four SNP in common also defining a polymorphic sequence block, present in S. brachistotrichum, $S$. nayaritense (Table 4; Supplementary Table S4), and S. stoloniferum. The R2-like, Rpi-abpt, and R2 alleles are classified in haplotypes D1 and E1.

\section{Validation of late blight resistance by effector recognition and detached leaf assay.}

In an attempt to link the presence of Rpi-blb haplotypes to late blight resistance, a set of 50 plants from our in vitro collection was screened. It included a molecular characterization by PCR amplification with Rpi-blb1, Rpi-blb2, and Rpi-blb3 gene-specific primers followed by sequencing the PCR fragment. An additional combination of Rpi-blb3 primers, Blb3 F/Ra, was used, with Ra being specific to Rpi-blb3 and its homolog R2-like (Lokossou et al. 2009), in order to pick up intermediates of Rpi-blb3 and R2-like. Phenotypic characterization was carried out through detached leaf assays with six $P$. infestans isolates (Supplementary Table S2) and agroinfiltration with Pi effectors interacting with Rpi-blbl and Rpi-blb3. The chosen $P$. infestans isolates were genetically very different from each other, as has been shown by simple-sequence repeat

Table 1. Allelic variation for Rpi-blb1 in Solanum bulbocastanum accessions and related species ${ }^{\mathrm{a}}$

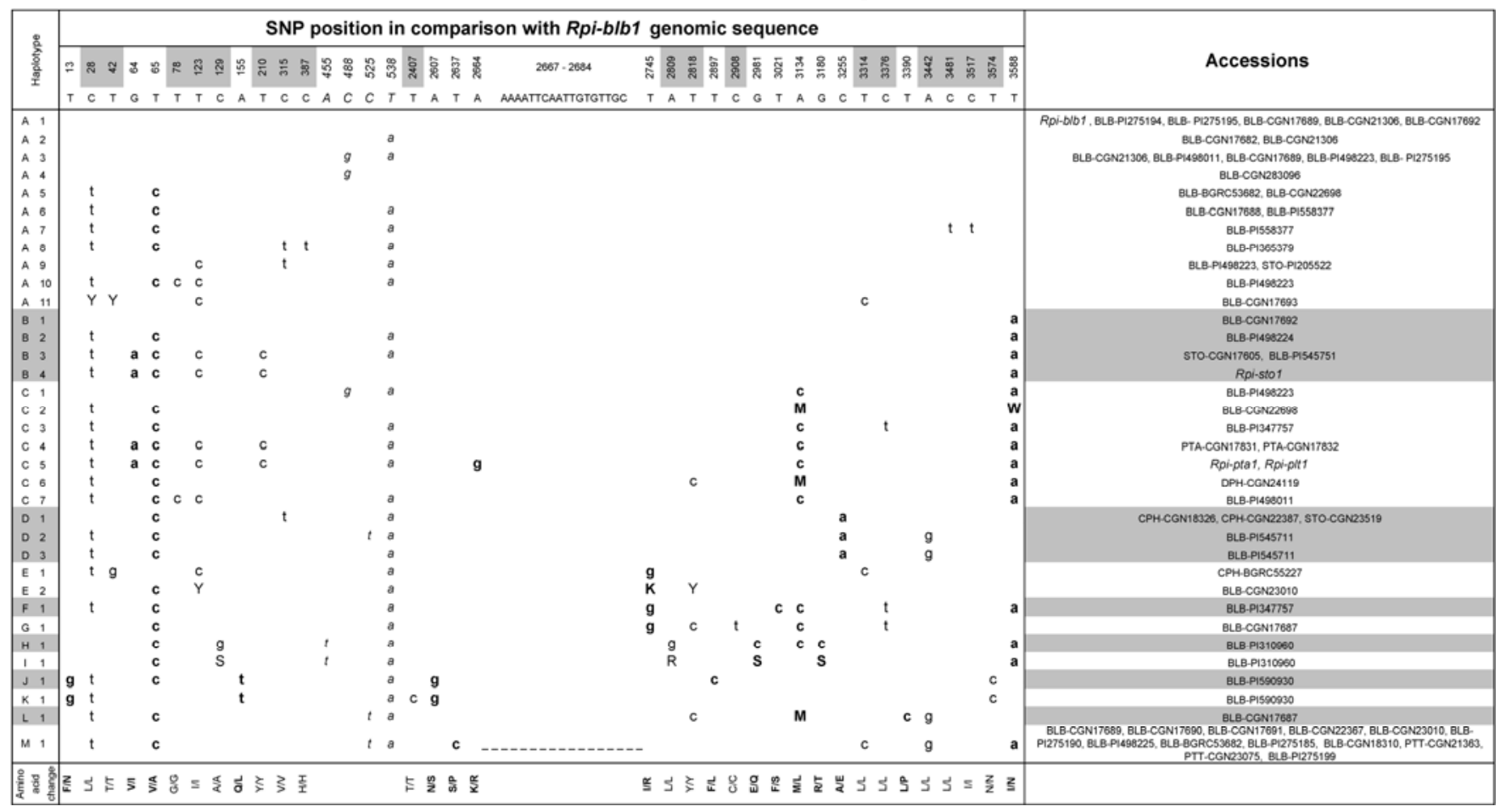

a The Rpi-blb1 sequence spans 1,709 bp in total, composed of two separate parts: i) from the start codon to position 520, derived from the primer 517/1519, with polymorphic nucleotides located in the intron sequence in italics; and ii) from position 2,404 to the stop codon, derived from the primer BLB1F/R and $1521 / 519$.

Table 2. Allelic variation for Rpi-blb2 in Solanum bulbocastanum accessions and related species ${ }^{\mathrm{a}}$

\begin{tabular}{|c|c|c|c|}
\hline \multirow{2}{*}{ 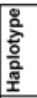 } & \multicolumn{2}{|c|}{ SNP position in comparison with Rpi-blb2 genomic sequence } & \multirow[b]{2}{*}{ Accessions } \\
\hline & $2226-2297$ & 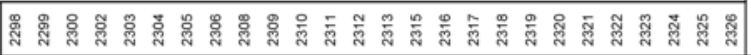 & \\
\hline A & TCTGGAAGAAGTGGTGAAAATTATTTGGATGATTTAATTTCCAGTAGCTTGGTAATTTGITTCAATGAGAT & $A \begin{array}{llllllllllllllllllllllllll}A & G & G & G & A & T & T & A & C & C & T & A & C & T & G & C & C & A & A & C & T & T & C & A & T & G \\
\end{array}$ & 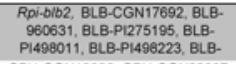 \\
\hline B & $\cdot$ & 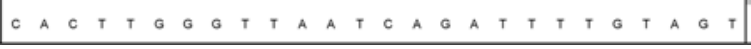 & $\begin{array}{l}\text { CPH-CGN18326, CPH-CGN22387, } \\
\text { CPH-BGRC55227 }\end{array}$ \\
\hline
\end{tabular}

a The Rpi-blb2 sequence spans 715 bp derived from the primers Blb2F/R. 
fingerprinting (Champouret et al. 2009), and displayed different virulence spectra with respect to the Rpi-blb genes tested. The Rpi-blb2 gene conferred resistance to the six isolates used and the Rpi-blbl and Rpi-blb3 gene conferred the resistance spectrum shown in Table 4. None of the tested plants contained Rpi-blb2, because no fragment was amplified with the primers Blb2F/R. Unfortunately, we observed background responses caused by the agroinfiltration of Avrblb2 in all the

Table 3. Allelic variation for Rpi-blb3 in Solanum bulbocastanum accessions and related species ${ }^{\mathrm{a}}$

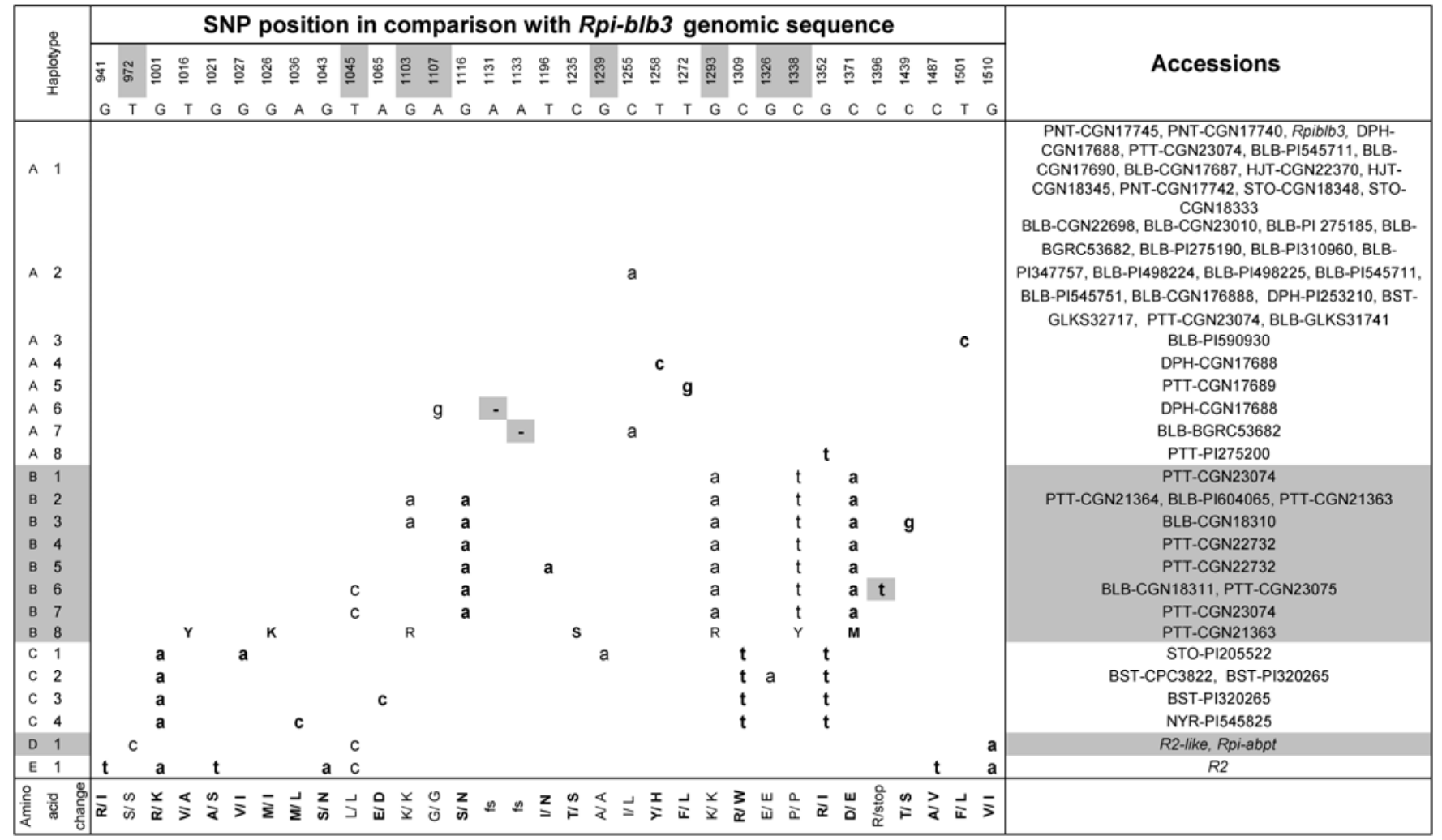

a The Rpi-blb3 sequence spans 618 bp derived from the primers Blb3F/R. The nucleotides of Rpi-blb gene sequences are in capital letters. Haplotype codes are indicated in the left column. Nucleotide positions are numbered according to the genomic sequences of the genes, beginning at the START codon and including introns in the case of Rpi-blb1 and Rpi-blb2. Amino acid changes are indicated on the bottom line. Single-nucleotide polymorphism (SNP) portions of the intron region are in italics. The position where SNPs did not change the amino acid are highlighted in light gray. SNPs resulting in nonsynonymous amino acid changes are indicated in bold. Solanum accessions in which the haplotypes where identified are indicated on the right column. Nucleotide abbreviations according to the IUB code are in capital letters: K, GT; M, AC; R, AG; S, GC; W,AT; Y, CT.

Table 4. Evaluation of representative Solanum genotypes by molecular characterization, effector agroinfection, and detached-leaf assay ${ }^{\mathrm{a}}$

\begin{tabular}{|c|c|c|c|c|c|c|c|c|c|c|c|c|c|c|c|c|c|}
\hline \multirow[b]{2}{*}{ Taxon } & \multirow[b]{2}{*}{ Accession number } & \multicolumn{3}{|c|}{ Specific amplification } & \multicolumn{2}{|c|}{ Sequence } & \multicolumn{4}{|c|}{ Effector Agro-infiltration } & \multicolumn{6}{|c|}{ Phytophtora infestans Detached leaf assay } & \multirow[b]{2}{*}{ Comments } \\
\hline & & $\begin{array}{c}\text { Rpi-bib1 } \\
1 / 1\end{array}$ & $\begin{array}{c}\text { Rpibib3 } \\
\text { F/R }\end{array}$ & $\begin{array}{l}\text { Rpiblb3 } \\
\text { F/Ra }\end{array}$ & $\begin{aligned} \text { Rpiblb1 } \\
\text { Haplo }\end{aligned}$ & Rpiblb3 & Avn-bib1 & Pi-Avr2 & R3a & R3a/Avr3a & PIC99177 & PIC99189 & PIC99183 & IPO-C & 90128 & UK7824 & \\
\hline $\begin{array}{l}\mathrm{BLB} \\
\mathrm{DPH}\end{array}$ & $\begin{array}{l}\text { CGN17692 (Blb8005-8) } \\
\text { CGN17688 (BBb99-256-3) }\end{array}$ & $\frac{10}{x}$ & $x$ & $\begin{array}{l}x \\
x \\
x\end{array}$ & A1 & A1 & +++ & $+\dot{+}$ & 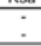 & $\begin{array}{l}++4+ \\
+++\end{array}$ & $\begin{array}{l}\mathrm{S} \\
\mathrm{Q}\end{array}$ & $\begin{array}{l} \\
\text { s }\end{array}$ & $\begin{array}{l}R \\
R\end{array}$ & $\begin{array}{l}R \\
\text { S }\end{array}$ & $\begin{array}{l}\mathrm{R} \\
\mathrm{R}\end{array}$ & $\begin{array}{l}R \\
\text { R }\end{array}$ & $\begin{array}{l}\text { Genotype containing Rpl-blb1 } \\
\text { Genotype containing Rpi-blb3 }\end{array}$ \\
\hline$\frac{H J T}{H T}$ & $\frac{C_{\text {CGN17688(B.699-256-3) }}}{\text { CGN22370 }}$ & & $\frac{x}{x}$ & & & $\frac{A 1}{A 1}$ & $\div$ & $++4+t$ & $\div$ & $+4+4$ & $\frac{2}{5}$ & $\frac{\pi}{5}$ & $\frac{K}{R}$ & $\frac{\mathrm{s}}{\mathrm{s}}$ & $\frac{R}{R}$ & $\frac{\mathrm{s}}{\mathrm{s}}$ & \\
\hline HUT & BGRC32671 & & $\hat{x}$ & & & A1 & : & +++ & . & . & s & R & $\mathrm{Rg}$ & s & $\hat{R}$ & s & \\
\hline HJT & CGN17717 & & $\hat{x}$ & $\mathrm{x}$ & & Â1 & . & +++ & . & ++ & R & $\mathrm{s}$ & $\mathbf{R}$ & s & $\hat{R}$ & s & \\
\hline sTo & CGN18333 & & $\hat{x}$ & & & A1 & . & +++ & . & 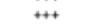 & s & R & $\hat{R}$ & s & $\hat{R}$ & s & \\
\hline PNT & CGN1833 & & $\hat{x}$ & $x$ & & A1 & + & + & . & $+4+$ & R & $\mathrm{R}$ & $\mathbf{R}$ & $\mathbf{R}$ & $\hat{\mathbf{R}}$ & R & Plants with Av12 recognition and Rpi-blb3 \\
\hline BST & CGN17681 & & $\hat{\mathrm{x}}$ & $\hat{\mathrm{x}}$ & & A2 2 & . & +++ & . & ++ & s & s & R & s & $\mathrm{Rq}_{\mathbf{q}}$ & s & fragment \\
\hline BLB & CGN18310 & & $\hat{x}$ & & & $\mathrm{~B} 2$ & . & ++ & . & +++ & R & R & $\hat{R}$ & $\mathrm{Q}$ & R & $\mathbf{R}$ & \\
\hline PTT & CGN21364 & & $\hat{x}$ & & & B2 & . & + & 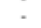 & ++ & $\mathbf{R}$ & $\mathrm{Q}$ & $\hat{R}$ & R & $\hat{\mathbf{R}}$ & s & \\
\hline BST & PI320265 & & & $\mathrm{x}$ & & $\mathrm{C} 2$ & : & +++ & 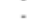 & +4 & n & R & $\mathbf{R}$ & $\mathrm{s}$ & $\mathbf{R}$ & $\mathrm{Q}$ & \\
\hline NYR & P1545825 & & $\mathrm{x}$ & & & $\mathrm{C4}$ & . & $+\cdots$ & - & *+* & a & $\mathrm{R}$ & $\mathbf{R}$ & s & $\mathbf{R}$ & $\mathbf{R}$ & \\
\hline sto & PI205522 & $x$ & $x$ & & A9 & C1 & +++ & +++ & - & n++ & Q & $R$ & $\mathbf{R}$ & R & $R$ & $\mathbf{R}$ & $\begin{array}{l}\text { Prant with Avr2 and Avribib1 recognition and Rpi- } \\
\text { bib1 and Rpt-bib3 fragments. }\end{array}$ \\
\hline BLB & CGN17689 & $\mathrm{x}$ & $\mathrm{x}$ & & A1 & A5 & +++ & . & . & +++ & $\mathbf{R}$ & $\mathbf{R}$ & $\mathbf{R}$ & $\mathbf{R}$ & $\mathbf{R}$ & $\mathbf{R}$ & Plants with Avreib1 recognition and Rpi-blb1 \\
\hline sto & CGN18348 & & $x$ & & & A1 & +++ & . & - & + & $\mathbf{R}$ & s & $\mathbf{R}$ & $\mathbf{R}$ & $\mathbf{R}$ & $\mathbf{R}$ & Plants with AvrBb1 recognition and no Rpl-blb1 \\
\hline BLB & CGN17693 & & & & & & + & . & . & + & $\mathbf{R}$ & $\mathbf{R}$ & $\hat{R}$ & R & R & R & fragment. \\
\hline STO & $c$ & & $x$ & & & A1 & ? & . & - & ++ & 0 & $\bar{R}$ & $\mathrm{~s}$ & $\mathrm{~s}$ & $\mathbf{R}$ & $\mathrm{R}$ & Thiants with Rpi-blb1 and/or Rpi-blb3 fragments. \\
\hline BLB & BGRC53682 & $x$ & $\hat{x}$ & $x$ & A5 & $\mathrm{A} 2$ & . & . & . & +++ & $\mathbf{R}$ & s & $\mathbf{R}$ & $\mathbf{R}$ & R & R & but without Avrolb1 or Pi-Avr2 recognition. \\
\hline BLB & & & & & & & - & . & ?. & $+4+$ & $\bar{R}$ & $\bar{R}$ & $\bar{R}$ & $\mathbf{R}$ & $\mathbf{R}$ & $\bar{R}$ & TPants containing dfferent late bioht resistancel \\
\hline $\mathrm{CPH}$ & BGRC55227 & & & & & & . & . & . & +++ & $\mathrm{Q}$ & $\mathrm{Q}$ & $\mathrm{s}$ & $\hat{R}$ & s & $\hat{R}$ & genes other than the testod Rpi-bib genes. \\
\hline काT & & & $x$ & & & B1 & . & $\theta$ & 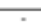 & +4 & $\mathrm{~s}$ & $\bar{s}$ & $\bar{s}$ & $\overline{\mathbf{S}}$ & S & $\mathrm{S}$ & \\
\hline BST & CPC 3822 & & $x_{x}^{x}$ & $\mathrm{x}$ & & $\begin{array}{ll}\text { nd } \\
\text { nd }\end{array}$ & : & +++ & : & $\ldots$ & s & s & s & s & s & s & Late blight suceptible plants \\
\hline PNT & $\overline{C G}$ & & & $\mathrm{x}$ & & & + & ++ & ++ & ++ & $\mathbf{R}$ & $\bar{R}$ & $\mathbf{R}$ & $\bar{R}$ & $\bar{R}$ & $\bar{R}$ & \\
\hline BLB & $\begin{array}{l}\text { CGN22367 } \\
\text { CN } 19\end{array}$ & & & $\begin{array}{l}x \\
x\end{array}$ & & & + & +4 & $\because$ & +4 & r & $\mathrm{a}$ & $\begin{array}{r}R \\
R\end{array}$ & $R$ & $R$ & $\begin{array}{r}R \\
R\end{array}$ & Plants not suitable for agro-infiltration \\
\hline
\end{tabular}

${ }^{a}$ Solanum accession taxons are indicated in the column from left to right; identification number (genotype number in bracket); results of the specific amplification of Rpi-blb1 by the primers combination 1/1' and Rpi-blb3 by Blb3 F/R and Blb3 F/Ra with Ra being specific to Rpi-blb3 and R2-like (Lokossou et al 2009); the haplotype identified after sequencing of the specific fragment (referring to Table 1); results of the effector agroinfection with Avr-blb1, Pi-Avr2, and the controls R3a and Pi-Avr3a/R3a together, are indicated by degree of response intensity from - = no response to +++ = clear hypersensitive reaction; results of the detached leaf assay conducted with the isolates PIC99177, PIC 99189, PIC 99183, IPO-C, 90128, and UK7824 scored as R (resistant), S (susceptible), Rq (quantitatively resistant), and Q (quantitative). Abbreviations: ND, sequences not determined; BLB, S. bulbocastanum; BST, S. brachistotrichum; CPH, S. cardiophyllum; DPH, S. bulbocastanum subsp. dolichophyllum; FEN, S. fendleri; HJT, S. hjertingii; NYR, S. nayaritense; PLT, S. polytrichon; PNT, S. pinnatisectum; PTA, S. papita; PTT, S. bulbocastanum subsp. partitum; STO, S. stoloniferum. CPH-BGRC55227 contains Rpi-blb2 haplotype B. 
plants tested (not shown); thus, Rpi-blb2 presence or absence could not be verified by effector recognition in wild Solanum spp. Results obtained for Rpi-blb1 and Rpi-blb3 are presented in Table 4 and show the diversity of possible interactions, classified in five categories.

The first category comprises plants harboring one or both of the Rpi-blbl and Rpi-blb3 genes, as judged from the marker analysis. They interacted with one or both of the Avrblb1 and Pi-Avr2 elicitors and displayed a resistance spectrum identical to or broader than the $S$. bulbocastanum-derived $R$ genes. Based on the assay with Avrblb1, three $S$. bulbocastanum and one $S$. stoloniferum plants contained Rpi-blbl. PCR amplification and sequencing strengthened the presence of functional Rpi-blb1 haplotypes, identified as A1 and A9. Their resistance spectrum matched with that of an $S$. bulbocastanum plant (CGN17692), which was confirmed to harbor Rpi-blbl (van der Vossen et al. 2003). However, they were resistant to isolates PIC99189 and PIC99177, known to break Rpi-blbl (Champouret et al. 2009), which suggests the presence of additional resistance factors in these genotypes. The Rpi-blb3 haplotypes A1, B2, C1, C2, C3, and C4 were found in 14 plants from S. bulbocastanum, S. brachistotrichum, S. hjertingii, $S$. nayaritense, and $S$. stoloniferum accessions. They all interact with Pi-Avr2 and display an identical or broader resistance spectrum compared with the progenitor used to isolate Rpiblb3, thus suggesting the presence of a functional Rpi-blb3 haplotype and additional late blight resistance factors.

From plants classified in the second category, fragments were amplified with primers specific for one or both Rpi-blbl and Rpi-blb3 genes but no interaction with Avrblb1 or Pi-Avr2 was observed. The Rpi-blb genes amplified might contain mutations preventing the interaction with the tested effectors. Moreover, these plants putatively contain late blight resistance genes other than the one tested, as judged from the responses to the isolates (Table 4).

The third category comprises resistant plants lacking Rpiblbl or Rpi-blb3, as judged from the marker assays and effector interaction. Interestingly, two $S$. bulbocastanum and two $S$. cardiophylum plants featured complete resistance to the full set of isolates. These plants probably contain late blight resistance genes other than the tested Rpi-blb genes. One $S$. cardiophyllum plant (CPH-BGRC55227) tested was positive for Rpiblb2 haplotype B and displays a resistance spectrum different from that of a Rpi-blb2-containing plant.

Late-blight-susceptible plants not containing any functional $R$ gene, as judged from the response with the tested isolates, but showing amplification with Rpi-blb3 primers are found in category 4. One $S$. brachistotrichum clone contained Rpi-blb3 haplotype $\mathrm{C} 2$ and interacted strongly with Pi-Avr2 but was completely susceptible to the set of $P$. infestans isolates tested. Three accessions from $S$. bulbocastanum subsp. partitum, two of $S$. brachistotrichum, and one of S. stoloniferum contained Rpi-blb3 haplotypes $\mathrm{B} 1, \mathrm{~B} 2, \mathrm{~B} 7$, and $\mathrm{C} 2$ but did not interact with Pi-Avr2 and displayed a susceptible phenotype when infected with the set of isolates.

The last category of plants was not suitable for agroinfiltration. The reactions with the effectors were nonspecific and resulted in a hypersensitive response to all the tested effectors or gave no reaction to control $P i-A v r / R$ gene co-infiltration (Table 4). However, plants showing resistance to all tested isolates are likely to contain new late blight resistance gene.

\section{Geographical distribution of the Rpi-blb genes.}

The three Rpi-blb genes were mainly present in the $S$. bulbocastanum accessions from Central Mexico (Fig. 2) and plants not containing the three studied Rpi-blb genes originated from the northern part of Mexico and the southern part of the United
States. Also, the allotetraploid species S. fendleri, which is found in the north of Mexico, lacks the Rpi-blb genes tested.

S. stoloniferum from the Durango region contained Rpi-blbl whereas Rpi-blb3 was present in S. hjertingii originating from Monterray, S. brachistotrichum from Chihuahua, and S. bulbocastanum subsp. partitum from Guatemala.

In order to see whether haplotypes diverge when they originate from more geographically distant areas, the haplotypes were phylogenetically mapped in Google Earth using Supramap (Janies et al. 2007). From the results, it can be seen that the M1 haplotype of Rpi-blbl is present in Central Mexico as well as in Guatemala and that the less-supported clade containing the $\mathrm{C}$ and B haplotypes from $S$. stoloniferum is confined to the upper part of Mexico. For Rpi-blb3, the haplotypes of group C originate from Central toward Northern Mexico, whereas haplotypes recognized as group B all are from Guatemala.

\section{DISCUSSION}

The use of gene-specific primers and gene functionality.

Gene-specific primers are powerful tools for the evaluation of the presence or absence of resistance genes (Arens et al. 2010). Subsequent sequencing of the fragment makes it possible to verify their identity, differentiate the haplotypes, and discard recognized pseudogenes, thus indicating the presence or absence of the most likely functional genes. We validated this approach by phenotyping 50 individual plants using effectors and detached leaf assays. The plants were also characterized for the presence of Rpi-blb1, Rpi-blb2, and Rpi-blb3 with markers. In the 50 cases, we only observed two cases for $R p i$ blbl in which the markers predicted the presence of the gene where there was no effector response. This indicates that there is a good but not $100 \%$ correlation between markers and phenotype for Rpi-blbl (Table 4). All plants tested negative when using the gene-specific markers for Rpi-blb2. Unfortunately, this could not be validated by an effector response due to background that was observed in the agroinfiltration experiment with Avrblb2. For Rpi-blb3, we found 13 cases in which there was amplification with the gene-specific primers but no response to the effector. There were three cases in which there was a response to the effector but no amplification of the genespecific fragment and one case in which we observed an effector response and no resistance in the detached leaf assay. An additional primer pair (Blb3 F/Ra) did amplify in some of the cases where there was no amplification with the Rpi-blb3-specific primers was found (Table 4), suggesting that similar but slightly different genes are present. This was clear from the sequence analysis of some of the fragments obtained with the Rpi-blb3-specific primers (e.g., the B and C haplotypes of Rpiblb3). These results reflect the complexity of the Rpi-blb3 gene family and underline the usefulness of the combined techniques to identify Rpi-blb3 from the other alleles of the cluster. However, it should be stressed that, in most cases where there was a discrepancy observed between marker assays and phenotypic assays, this was outside $S$. bulbocastanum.

Discrepancies between molecular and functional assays can have several causes. For example, plants containing an $R$ allelespecific fragment are for some reason unable to interact with the Avr-protein. In such cases, the $R$-gene fragment found is probably not translated into a protein interacting with the Avr protein, as was also observed by Hall and associates (2009) in H. arabidopsidis. Also, recognition specificity of different effectors by different alleles may be an important factor, as was previously demonstrated for the RPMI locus of Arabidopsis thaliana (Bisgrove et al. 1994; Grant et al. 1995), the $L$ locus in flax (Dodds et al. 2004), and the Pto locus in tomato (Kim et al. 2002; Ronald et al. 1992). 


\section{Distribution of Rpi-blb genes in Solanum spp.}

Our study provides a clear picture of the distribution of late blight resistance genes so far isolated from $S$. bulbocastanum. It shows that Rpi-blb1, Rpi-blb2, and Rpi-blb3 have a very limited distribution among species. Their spread is restricted to the Mexican diploid species and the polyploid Longipedicellata group and confined to Central America. The occurrence of similar haplotypes in different diploid species may be explained by the fact that these species are able to form interspecific hybrids, especially $S$. bulbocastanum and $S$. cardiophyllum (Graham 1965). The presence of both Rpi-blbl and Rpi-blb3 in the polyploid Longipedicellata may be explained by the fact that this group of Solanum section Petota is of allotetraploid origin. It has been shown that $S$. hjertingii, for example, consists of an $S$. verrucosum-like and an $S$. cardiophyllum-like genome (Pendinen et al. 2008). Wang and associates (2008) suggested that S. bulbocastanum may be one of the parental species of the allotetraploid S. stoloniferum. The observation that the late blight resistance genes evaluated are confined to Central America might be true for the distribution of other $R$ genes as well.

\section{Rpi-blb genes are found}

in different frequencies in $S$. bulbocastanum populations.

Gene bank accessions used in this study consist of plant material that has been generatively multiplied by the gene bank prior to usage. In the Netherlands, at the Centre for Genetic Resources (CGN), this is done without any P. infestans pressure, because protective spraying is applied every week. This might have resulted in slight frequency changes in the presence of the Rpi-blb genes compared with the actual situation in Mexico.

We assessed the frequency in which the different genes are present in the $S$. bulbocastanum accessions under study. Individual plants containing all three Rpi-blb genes have been found at very low frequency (less than $1 \%$ ) and in two $S$. bulbocastanum accessions only, probably because of the rarity of Rpi-blb2. The Rpi-blb1 and Rpi-blb3 genes have been detected together in $27 \%$ of the $S$. bulbocastanum plants analyzed (52\% of the accessions). Only in S. bulbocastanum PI498225 did all individual plants contain Rpi-blbl and Rpi-blb3, suggesting that accumulation of these genes in $S$. bulbocastanum is a rare event. On the other hand, our functional test with the 50 plants frequently showed a broader resistance spectrum than expected with the tested Rpi-blb genes, indicating the presence of other, unknown, Rpi genes.

Almost all the accessions tested contain putative resistant and susceptible individuals. This might reflect a strongly fluctuating $P$. infestans pressure.

The susceptible haplotype of Rpi-blbl, denoted as M1, is abundantly present and scattered around in Central America.

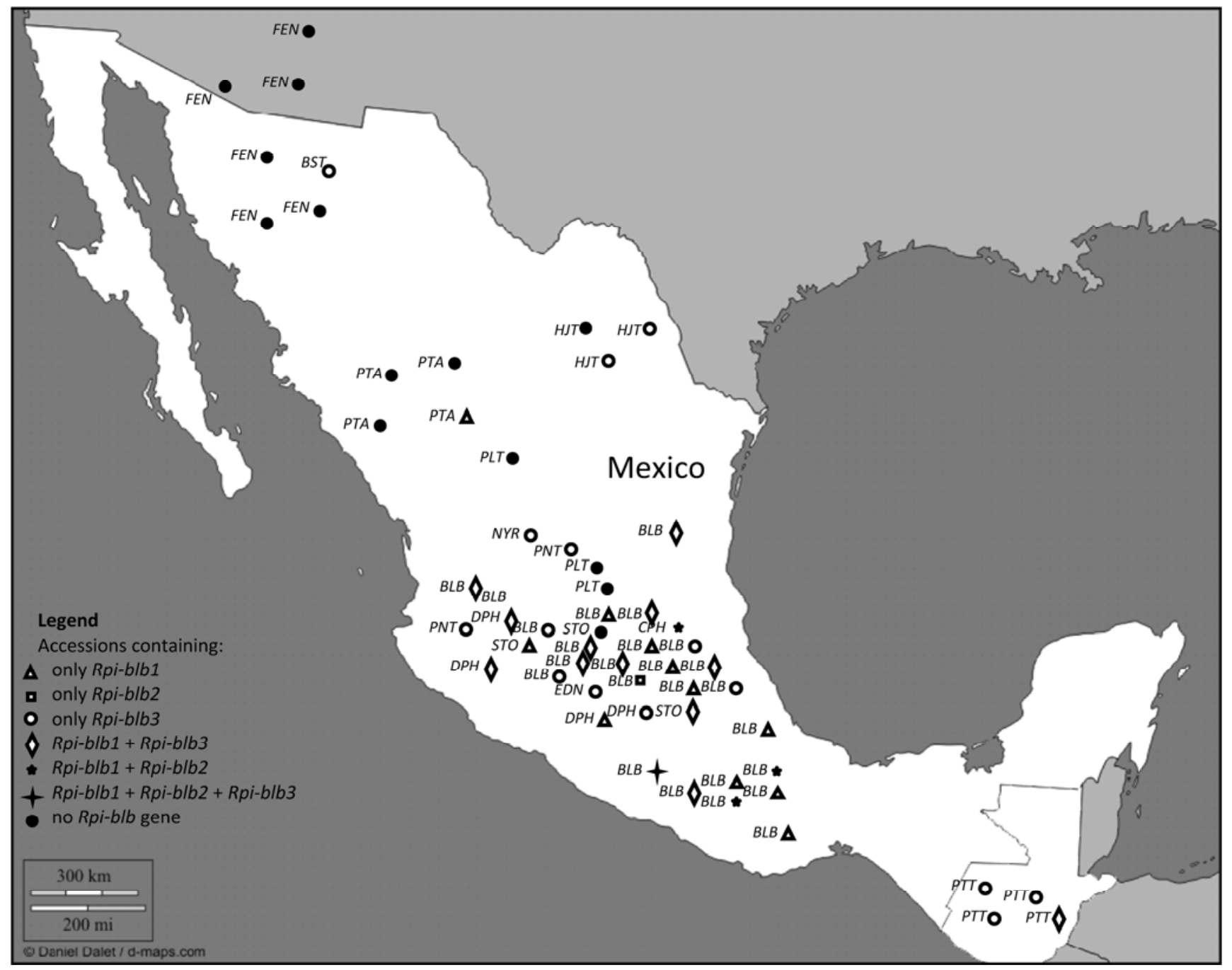

Fig. 2. Geographical location of the Solanum accessions under study containing only Rpi-blb1 (triangles), only Rpi-blb2 (squares), only Rpi-blb3 (white-filled dots), Rpi-blb1 and Rpi-blb3 (lozenges with a white center), Rpi-blb1 and Rpi-blb2 (stars), the three Rpi-blb genes (cross), and the accessions not containing any Rpi-blb gene (solid black dots). 
Long-lived coexistence of resistant and susceptible alleles has been observed in other species as well, such as A. thaliana (Henk et al. 1999; Stahl et al. 1999) and wheat (Yahiaoui et al. 2006), and may be related to plant fitness in the absence of selective pressure (Tian et al. 2003; McDowell and Simon 2006; Kramer et al. 2009).

\section{Evolution of Rpi-blb genes.}

Sequence analysis of the fragments obtained for the Rpi-blbl and Rpi-blb3 genes suggests an evolution through recombination and point mutations. In this respect, there are clear differences between the two genes. Rpi-blbl is thought to have resulted from a recombination event involving $R G A 1-b l b$ and RGA3-blb (van der Vossen et al. 2003), and sequence analysis (Table 1) suggests a further evolution through point mutations, an evolutionary pattern typical for a type II resistance gene as described for $R$ genes in natural lettuce populations (Kuang et al. 2004).

The situation with Rpi-blb3 is more complex than with Rpi-blb1 and most likely related to the complex nature of the cluster in which the gene is present. In this cluster, several genes have almost identical sequences (Lokossou et al. 2009). Although all sequence information available has been taken into account for the design of the gene-specific primers for Rpi-blb3, it cannot be excluded that some variants may not be discriminated by these primers. In Solanum spp. as a whole, even more Rpi genes have been mapped to the Rpiblb3 cluster. Examples are Rpi-demfl from S. demissum (Hein et al. 2007), Rpi-snk1 (Jacobs et al. 2010), and QTLs from S. microdontum (Colon et al. 1995; Micheletto et al. 2000; Sandbrink et al. 2000). Such resistances might represent $R$ genes which are homologues or recombinants sharing ancestry with $R p i-b l b 3$ as well as $R$ genes that have evolved independently and interact with other or the same effectors. In the same way, functional Pm3 resistance genes independently evolved in wild tetraploid wheat and domesticated bread wheat (Yahiaoui et al. 2009).

The presence of conserved SNP patterns among the haplotypes suggests independent recombinations between ancestors of Rpi-blb3. In wheat, recombination has been shown to have resulted in the birth of the $L r 21$ resistance gene (Huang et al. 2009). This gene was found to be a chimera between two nonfunctional haplotypes.

Recent studies show that the recombination level at $R$ clusters is increased following pathogen infection, suggesting a mechanism that induces temporary genome instability in response to extreme stress (Lucht et al. 2002; Kovalchuk et al. 2003). This instability might well be connected to the high intensity of transcription of some $R$ genes seen just after infection (Kramer et al. 2009), in which the genome must be temporarily accessible for efficient transcription. It is conceivable that, depending on the disease pressure, we have a fast pattern of evolution of $R$-gene clusters dominated by sequence exchange or a slow pattern of evolution dominated by point mutations. Both evolutionary mechanisms appear to have shaped the Rpi-blb1 and Rpi-blb3 clusters. Additionally, the distinction between type I and II seems rather artificial; empirical sequence data suggests a continuum between the two types. Likewise, comparisons of sequences obtained through allele mining conducted at the Pm3 locus in wheat (Bhullar et al. 2009) show differences that originated from point mutations and illegitimate recombination.

The absence of mutation or recombination in the Rpi-blb2 fragment amplified from $S$. bulbocastanum and the low percentage of Rpi-blb2-containing plants show that this gene emerged recently and didn't evolve through point mutations yet.
New $P$. infestans $R$ genes identified.

In our analysis, $76 \%$ of late-blight-resistant genotypes cannot be explained by only the presence of the Rpi-blb1, Rpi-blb2, and Rpi-blb3 genes. Clear examples are $S$. bulbocastanum accessions CGN23010 and P1275199; however, genotypes from CGN17689 and CGN21306 also contain additional resistance genes, because their resistance spectrum is different from Rpiblb1, Rpi-blb2, or Rpi-blb3. This confirms that S. bulbocastanum is a rich source of late blight resistance genes, as indicated by Budin (2002). The $S$. stoloniferum accession PI205522, containing Rpi-blbl and Rpi-blb3, based on the marker assays, contains an additional gene based on the resistance spectrum observed (Table 4). The gene involved is probably a paralog of R4 ${ }^{\mathrm{MA}}$ (Van Poppel et al. 2009) because it confers resistance to isolate PIC99189 (avirulent on R4 ${ }^{\mathrm{MA}}$ ) and a hypersensitive response with Avr4 effector (van Poppel et al. 2008) was found (unpublished results). The possibility cannot be excluded that the recently described gene Rpi-btl (Oosumi et al. 2009) is responsible for some of the resistant phenotypes found in $S$. bulbocastanum. Because we found Rpi-blbl and Rpi-blb3 in species related to $S$. bulbocastanum, it would make sense that some of newly identified resistance genes in S. bulbocastanum might already have been identified in related species, such as the resistances found in $S$. cardiophyllum and $S$. pinnatisectum (Kuhl et al. 2001).

Allele mining in Petota germplasm with primers identifying known $R$ genes allows the potato breeder to identify more amenable species for introgression breeding. For example, S. bulbocastanum hardly crosses with cultivated potato (Hermsen and Ramanna 1973; Helgeson et al. 1998), and the identification of Rpi-blb1 alleles in S. stoloniferum largely facilitates the introgression breeding of Rpi-blbl-like resistance genes for commercial usage (Vleeshouwers et al. 2008; Wang et al. 2008).

Given the high diversity of genes found, some promising $R$ genes might not even be present in the germplasm collections. New, extensive collections in hot spots of co-evolution and subsequent evaluations will undoubtedly provide new sources of resistance that can be used in classical and advanced resistance breeding (Haverkort et al. 2009).

\section{MATERIALS AND METHODS}

\section{Plant material.}

The Solanum spp. used were obtained from the CGN. DNA samples of $14 \mathrm{~S}$. bulbocastanum accessions originating from the United States potato GenBank, in Sturgeon Bay, WI were supplied by A. del Rio, University of Wisconsin, (referred to as PI accessions in Tables 1 through 3). When available, up to 10 genotypes per accession were used. Individual clones listed in Table 4 were retrieved from the plant material described by Jacobs and associates (2008) for in vivo experiments consisting of detached leaf assays and effector agroinfiltrations.

\section{PCR amplification, \\ DNA sequencing, and computer analyses.}

Specific primers used to amplify fragments of the three $R$ genes studied are listed in Supplementary Table S3 and Figure 3. Primers were designed to specifically amplify part of the genes under study and not the known paralogous sequences; for example, not RGA-3 and RGA-4 in the case of Rpi-blbl (van der Vossen et al. 2003), the $15 \mathrm{Mi}$ - homologs of Rpi-blb2 (van der Vossen et al. 2005), and the 24 Rpi-blb3 homologs known (Lokossou et al. 2009). This requirement considerably reduced the length of the fragment that could be sequenced from each gene: 1,709 bp for Rpi-blb1, $715 \mathrm{bp}$ for $R p i-b l b 2$, and 618 bp for Rpi-blb3. PCR products of randomly selected positive genotypes within an accession were 
sequenced directly to confirm their identity and to identify SNP. Sequencing reactions were performed using a dye terminator cycle-sequencing reaction kit (Perkin-Elmer, Pt Biosystem, Warrington, U.K.) and analyzed on an ABI3700 automated sequencer (Applied Biosystem, La Jolla, CA, U.S.A.). Multiple sequence alignments were conducted using DNASTAR Lasergen MegAlign version 8.0.2, permitting the distinction of the SNP compared with the cloned Rpi-blb gene sequence (Rpi-blb1, GenBank accession number AY426259.1; Rpi-blb2, GenBank: DQ122125.1; and Rpiblb3, GenBank: FJ536326.1). Unique sequences are reported in Tables 1 and 2. Nucleotides are numbered from the first nucleotide of the coding sequence of the cloned gene. The synonymous or silent SNP not leading to a change in amino acid were differentiated from the nonsynonymous SNP.

\section{Resistance assay.}

Detached leaf assays were used to determine the resistance phenotypes of the tested genotypes with eight $P$. infestans isolates: PIC99177, PIC99189, PIC99183, IPO-C, 90128, and UK7824. Inoculum preparations and inoculations were performed as described by Vleeshouwers and associates (1999). Six days after inoculation, infection symptoms were scored on a scale from 1 to 8 , to discriminate from very susceptible until very resistant. Score 1 to 3 meant clear infection, with $1=$ heavily sporulating lesion and $3=$ ample sporulating lesion, thus characterized as susceptible (S). Scores 4 and 5 were not clearly susceptible or resistant and, therefore, called quantitative (Q). Resistant (R) phenotypes were characterized by score 6, with hypersensitive lesions larger than $10 \mathrm{~mm}$; score 7, lesions between 4 and $10 \mathrm{~mm}$; and score 8, with hypersensitive lesions smaller than $4 \mathrm{~mm}$ in diameter.

\section{Effector agroinfiltration on wild species.}

The Avr effectors Avrblbl (Vleeshouwers et al. 2008) and Avrblb2 were cloned into vector pK7WG2 and $P i$-Avr2 was cloned into vector pGRAB (Lokossou et al. 2009). The resistance genes $R 3 a$ (Huang et al. 2004) and its cognate effector Pi-Avr3a (Bos et al. 2006) were cloned into the vector pGRAB (provided by S. N. Chapman) and used as control for the agrotransformation efficiency. The constructs were transferred into the same A. tumefaciens AGL1 carrying pVirG. The different constructs were grown in Luria-Bertani (LB) medium supplemented with choramphenicol at $75 \mathrm{mg} /$ liter, kanamycin at 50 $\mathrm{mg} / \mathrm{liter}$, and tetracycline at $4 \mathrm{mg} / \mathrm{liter}$ for $P i-A v r 2, A v r 3 a$, and $R 3 a$, and with spectinomycin at $100 \mathrm{mg} /$ liter, chloramphenicol at $75 \mathrm{mg} / \mathrm{liter}$, and tetracycline at $4 \mathrm{mg} / \mathrm{liter}$ for Avrblbland Avrblb2. Inoculum of the first experiment was prepared using the growth of bacteria in LB media (agar at $15 \mathrm{~g} /$ liter, bacterial peptone at $10 \mathrm{~g} / \mathrm{liter}, \mathrm{NaCl}$ at $10 \mathrm{~g} / \mathrm{liter}$, and yeast extract at 5 $\mathrm{g} /$ liter) until stationary phase and subsequently spun down at 3,600 rpm. Bacteria were resuspended in MMA media $(10 \mathrm{mM}$ acetosyringone, $10 \mathrm{mM}$ morpholineethanesulfonic acid, and MS salts at $5 \mathrm{~g} / \mathrm{liter}$ ). In the second experiment, the bacteria were precultured in $3 \mathrm{ml}$ of LB, after which they were transferred to yeast-beef extract medium (beef extract at $5 \mathrm{~g} /$ liter, yeast extract at $1 \mathrm{~g} /$ liter, sucrose at $5 \mathrm{~g} / \mathrm{liter}$, bacterial peptone at $5 \mathrm{~g} / \mathrm{liter}$, and $2 \mathrm{mM} \mathrm{MgSO}$ ) and allowed to grow to an optical density at $600 \mathrm{~nm}\left(\mathrm{OD}_{600}\right)$ of 0.4 to 2.0 ; afterward, they were spun down at 3,600 rpm for $10 \mathrm{~min}$ and, subsequently, resuspended in MMA medium. Individual constructs were prepared at an $\mathrm{OD}_{600}$ of 0.2 and the combination Pi-Avr3a /R3a at 0.3 were used to infiltrate 3 - to 5 -week-old wild species plants, reaching their ninth leaf stage (Vleeshouwers and Rietman 2009). Specific recognition of the $A v r$ gene by a putative $R$ gene present induced the hypersensitive cell death response from 5 days post infiltration. Response intensity was scored in percentage of infiltrated area showing cell death: 0 to $20 \%$ of dark lesion were characterized by,- 21 to $35 \%$ by,+ 36 to $65 \%$ by ++ , and 66 to $100 \%$ by +++ .

\section{Geographical localization of the accessions.}

Geographical origin (latitude and longitude) of the accessions was retrieved from the CGN website and from literature (Rodriguez and Spooner 1997; Hijmans et al. 2007). The desktop application Google Earth was used to visualize the location of the genotypes. Different tags were associated with genotypes containing Rpi-blb1, Rpi-blb2, Rpi-blb3, or their combinations.

We used the internet application SUPRAmap (Janies et al. 2007) in order to associate the different haplotypes with their geographic distribution. The out-group for Rpi-blbl and Rpiblb3 was assigned by performing a phylogenetic analysis in Mega Software (version 4), using the "minimal evolution" option with standard parameters. The classification described in Tables 1 and 3 was used to illustrate the geographical localization of groups B and C (Table 3) and the M1 clade from Table 1 is highlighted to illustrate the spread of the M1 allele.

\section{ACKNOWLEDGMENTS}

We thank D. Janies (Department of Biomedical informatics, Ohio State University, U.S.A.) for his kind help and access to the SUPRAmap website; the Scottish Crop Research Institute (SCRI) and The Sainsbury Laboratory (TSL) for giving us the opportunity to use the effectors $P i$-Avr2 and Avrblb2, respectively; N. Champouret (Wageningen UR Plant Breeding) for cloning Avrblb2 into the expression vector; and P. R. J. Birch, G. Kessel, and F. Govers for providing Phytophthora isolates. Funding for this project was provided by the EU (contract no. FOOD-CT-2005-513959 BIOEXPLOIT) for the Bioexploit project and a grant from the Wageningen University Fund.

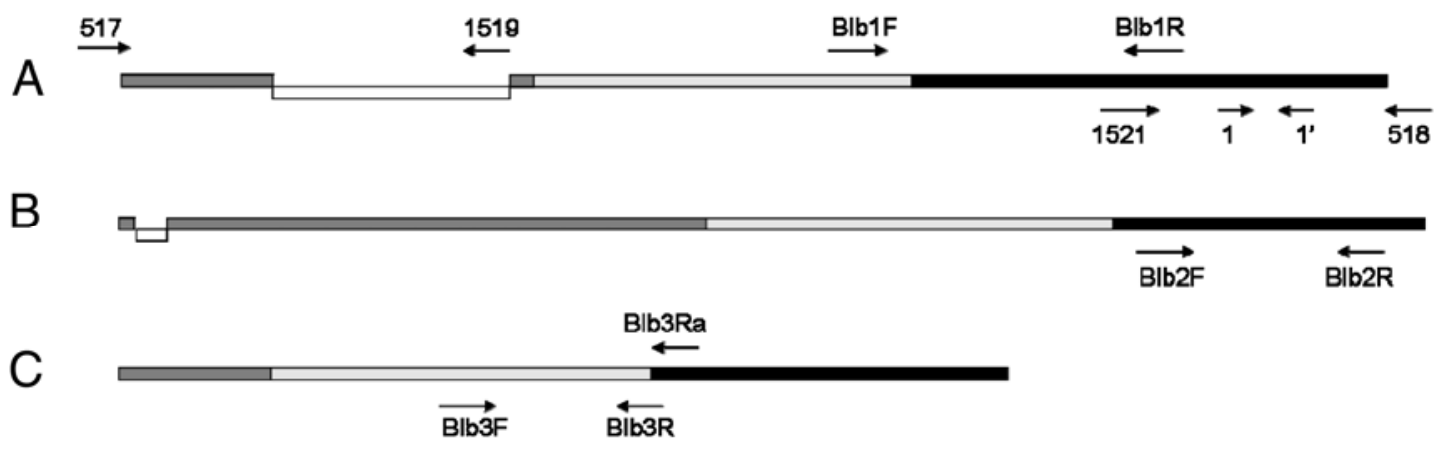

Fig. 3. Location of Rpi-blb gene-specific primers. A, Rpi-blb1; B, Rpi-blb2; and C, Rpi-blb nucleotide sequences are from the start to the stop codon and drawn to scale. Regions corresponding to the leucine zipper or the coil-coiled domain, the intron, the nucleotide-binding site domain, and the leucine-rich repeat domain are highlighted in gray, white, light gray, and black, respectively. Primer pairs used in this study are 517/1519, Blb1 F/Blb1 R, 1521/518, 1/1', Blb2F/Blb2R, Blb3F/Blb3R, and Blb3F/Blb3Ra. 


\section{LITERATURE CITED}

Allen, R. L., Meitz, J. C., Baumber, R. E., Hall, S. A., Lee, S. C., Rose, L. E., and Beynon, J. L. 2008. Natural variation reveals key amino acids in a downy mildew effector that alters recognition specificity by an Arabidopsis resistance gene. Mol. Plant Pathol. 9:511-523.

Arens, P., Mansilla, C., Deinum, D., Cavellini, L., Moretti, A., Rolland, S., van der Schoot, H., Calvache, D., Ponz, F., Collonnier, C., Mathis, R., Smilde, D., Caranta, C., and Vosman, B. 2010. Development and evaluation of robust molecular markers linked to disease resistance in tomato for distinctness, uniformity and stability testing. Theor. Appl. Genet. 120:655-664. DOI 10.1007/s00122-009-1183-2

Bai, Y. L., van der Hulst, R., Bonnema, G., Marcel, T. C., Meijer-Dekens, F., Niks, R. E., and Lindhout, P. 2005. Tomato defense to Oidium neolycopersici: Dominant $O \mathrm{Ol}$ genes confer isolate-dependent resistance via a different mechanism than recessive ol-2. Mol. Plant-Microbe Interact. 18:354-362.

Bhullar, N. K., Street, K., Mackay, M., Yahiaoui, N., and Keller, B. 2009. Unlocking wheat genetic resources for the molecular identification of previously undescribed functional alleles at the Pm3 resistance locus. Proc. Natl. Acad. Sci. U.S.A. 106:9519-9524.

Bisgrove, S. R., Simonich, M. T., Smith, N. M., Sattler, A., and Innes, R. W. 1994. A disease resistance gene in Arabidopsis with specificity for 2 different pathogen avirulence genes. Plant Cell 6:927-933.

Bos, J. I. B., Kanneganti, T.-D., Young, C., Cakir, C., Huitema, E., Win, J., Armstrong, M. R., Birch, P. R. J., and Kamoun, S. 2006. The C-terminal half of Phytophthora infestans RXLR effector AVR3a is sufficient to trigger R3a-mediated hypersensitivity and suppress INF1-induced cell death in Nicotiana benthamiana. Plant J. 48:165-176.

Brouwer, D. J., Jones, E. S., and St Clair, D. A. 2004. QTL analysis of quantitative resistance to Phytophthora infestans (late blight) in tomato and comparisons with potato. Genome 47:475-492.

Budin, K. Z. 2002. Genetic foci of Solanum species, Petota Dumort, resistant to Phytophthora infestans (Mont.) De Bary. Genet. Res. Crop Evol. 49:229-235.

Caicedo, A. L. 2008. Geographic diversity cline of $R$ gene homologs in wild populations of Solanum pimpinellifolium (Solanaceae). Am. J. Bot. 95:393-398.

Celebi-Toprak, F., Slack, S. A., and Jahn, M. M. 2002. A new gene, $N y_{t b r}$, for hypersensitivity to potato virus Y from Solanum tuberosum maps to chromosome IV. Theor. Appl. Genet. 104:669-674.

Champouret, N., Bouwmeester, K., Rietman, H., van der Lee, T., Maliepaard, C., Heupink, A., van de Vondervoort, P. J. I., Jacobsen, E., Visser, R. G. F., van der vossen, E. A. G., Govers, F., and Vleeshouwers, V. G. A. A. 2009. Phytophthora infestans isolates lacking class I IpiO variants are virulent on Rpi-blb1 potato. Mol. Plant-Microbe Interact. $22: 1535-1545$.

Colon, L. T., Jansen, R. C., and Budding, D. J. 1995. Partial resistance to Late Blight (Phytophtora infestans) in hybrid progenies of 4 SouthAmerican Solanum species crossed with diploid Solanum tuberosum Theor. Appl. Genet. 90:691-698.

Colton, L. M., Groza, H. I., Wielgus, S. M., and Jiang, J. M. 2006 Marker-assisted selection for the broad-spectrum potato late blight resistance conferred by gene $R B$ derived from a wild potato species. Crop Sci. 46:589-594.

Dickinson, M., Jones, D., and Jones, J. 1993. Close linkage between the $C f-2 / C f-5$ and $M i$ resistance loci in tomato. Mol. Plant-Microbe Interact. 6:341-347.

Dodds, P. N., Lawrence, G. J., Catanzariti, A. M., Ayliffe, M. A., and Ellis, J. G. 2004. The Melampsora lini AvrL567 avirulence genes are expressed in haustoria and their products are recognized inside plant cells. Plant Cell 16:755-768.

Ellis, J. G., Lawrence, G. J., Luck, J. E., and Dodds, P. N. 1999. Identification of regions in alleles of the flax rust resistance gene $L$ that determine differences in gene-for-gene specificity. Plant Cell 11:495-506.

Ernst, K., Kumar, A., Kriseleit, D., Kloos, D. U., Phillips, M. S., and Ganal, M. W. 2002. The broad-spectrum potato cyst nematode resistance gene (Hero) from tomato is the only member of a large gene family of NBSLRR genes with an unusual amino acid repeat in the LRR region. Plant J. 31:127-136

Graham, K. M. 1965. Experimental hybridization in certain diploid Mexican solanum species. Euphytica 14:113-119.

Grant, M. R., Godiard, L., Straube, E., Ashfield, T., Lewald, J., Sattler, A., Innes, R. W., and Dangl, J. L. 1995. Structure of the Arabidopsis Rpm1 gene enabling dual-specificity disease resistance. Science 269:843-846.

Hall, S. A., Allen, R. L., Baumber, R. E., Baxter, L. A., Fisher, K., BittnerEddy, P. D., Rose, L. E., Holub, E. B., and Beynon, J. 2009. Maintenance of genetic variation in plants and pathogens involves complex networks of gene-for-gene interactions. Mol. Plant Pathol. 10:449-457.
Haverkort, A. J., Struik, P. C., Visser, R. G. F., and Jacobsen, E. 2009. Applied biotechnology to combat late blight in potato caused by Phytophthora infestans. Potato Res. 52:249-264.

Hein, I., McLean, K., Chalhoub, B., and Bryan, G. J. 2007. Generation and screening of a BAC library from a diploid potato clone to unravel durable late blight resistance on linkage group IV. Int. J. Plant Genomics, Vol. 2007, Article ID 51421:5 pages. doi:10.1155/2007/51421.

Helgeson, J. P., Pohlman, J. D., Austin, S., Haberlach, G. T., Wielgus, S. M., Ronis, D., Zambolim, L., Tooley, P., McGrath, J. M., James, R. V., and Stevenson, W. R. 1998. Somatic hybrids between Solanum bulbocastanum and potato: A new source of resistance to late blight. Theor Appl. Genet. 96:738-742.

Henk, A. D., Warren, R. F., and Innes, R. W. 1999. A new Ac-like transposon of Arabidopsis is associated with a deletion of the RPS5 disease resistance gene. Genetics 151:1581-1589.

Hermsen, J. G. T., and Ramanna, M. S. 1973. Double-bridge hybrids of Solanum bulbocastanum and cultivars of Solanum tuberosum. Euphytica 22:457-466.

Hijmans, R. J., Gavrilenko, T., Stephenson, S., Bamberg, J., Salas, A., and Spooner, D. M. 2007. Geographical and environmental range expansion through polyploidy in wild potatoes (Solanum section Petota). Global Ecol. Biogeogr. 16:485-495.

Huang, S., Vleeshouwers, V. G. A. A., Werij, J. S., Hutten, R. C. B., Eck, H. J. v., Visser, R. G. F., and Jacobsen, E. 2004. The $R 3$ resistance to Phytophthora infestans in potato is conferred by two closely linked $R$ genes with distinct specificities. Mol. Plant-Microbe Interact. 17:428435 .

Huang, L., Brooks, S., Li, W., Fellers, J., Nelson, J. C., and Gill, B. 2009. Evolution of new disease specificity at a simple resistance locus in a crop-weed complex: Reconstitution of the $\operatorname{Lr} 21$ gene in wheat. Genetics 182:595-602.

Jacobs, M., Vosman, B., Vleeshouwers, V., Visser, R., Henken, B., and van den Berg, R. 2010. A novel approach to locate Phytophthora infestans resistance genes on the potato genetic map. Theo. Appl. Genet. 120:785-796. DOI 10.1007/s00122-009-1199-7

Jacobs, M. M. J., van den Berg, R. G., Vleeshouwers, V. G. A. A., Visser, M., Mank, R., Sengers, M., Hoekstra, R., and Vosman, B. 2008. AFLP analysis reveals a lack of phylogenetic structure within Solanum section Petota. BMC Evol. Biol. 18479504 8:145.

Janies, D., Hill, A. W., Guralnick, R., Habib, F., Waltari, E., and Wheeler, W. C. 2007. Genomic analysis and geographic visualization of the spread of avian influenza (H5N1). Syst. Biol. 56:321-329.

Kim, Y. J., Lin, N. C., and Martin, G. B. 2002. Two distinct Pseudomonas effector proteins interact with the Pto kinase and activate plant immunity. Cell 109:589-598.

Kovalchuk, I., Kovalchuk, O., Kalck, V., Boyko, V., Filkowski, J., Heinlein, M., and Hohn, B. 2003. Pathogen-induced systemic plant signal triggers DNA rearrangements. Nature 423:760-762.

Kramer, L. C., Choudoir, M. J., Wielgus, S. M., Bhaskar, P. B., and Jiang, J. 2009. Correlation between transcript abundance of the RB gene and the level of the RB-mediated late blight resistance in potato. Mol. PlantMicrobe Interact. 22:447-455.

Kruijt, M., Kip, D. J., Joosten, M. H. A. J., Brandwagt, B. F., and de Wit, P. J. G. M. 2005. The $C f-4$ and $C f-9$ resistance genes against Cladosporium fulvum are conserved in wild tomato species. Mol. Plant-Microbe Interact. 18:1011-1021.

Kuang, H. H., Woo, S. S., Meyers, B. C., Nevo, E., and Michelmore, R. W. 2004. Multiple genetic processes result in heterogeneous rates of evolution within the major cluster disease resistance genes in lettuce. Plant Cell 16:2870-2894.

Kuhl, J., Hanneman, R., and Havey, M. 2001. Characterization and mapping of Rpi1, a late-blight resistance locus from diploid (1EBN) Mexican Solanum pinnatisectum. Mol. Genet. Genomics 265:977985.

Lokossou, A. A., Park, T. H., van Arkel, G., Arens, M., Ruyter-Spira, C., Morales, J., Whisson, S. C., Birch, P. R. J., Visser, R. G. F., Jacobsen, E., and van der Vossen, E. A. G. 2009. Exploiting knowledge of $R / A v r$ genes to rapidly clone a new LZ-NBS-LRR family of late blight resistance genes from potato linkage group IV. Mol. Plant-Microbe Interact. 22:630-641.

Lucht, J. M., Mauch-Mani, B., Steiner, H.-Y., Metraux, J.-P., Ryals, J., and Hohn, B. 2002. Pathogen stress increases somatic recombination frequency in Arabidopsis. Nat. Genet. 30:311-314.

Luck, J. E., Lawrence, G. J., Dodds, P. N., Shepherd, K. W., and Ellis, J. G. 2000. Regions outside of the leucine-rich repeats of flax rust resistance proteins play a role in specificity determination. Plant Cell 12:1367-1377.

Mauricio, R., Stahl, E. A., Korves, T., Tian, D. C., Kreitman, M., and Bergelson, J. 2003. Natural selection for polymorphism in the disease resistance gene Rps 2 of Arabidopsis thaliana. Genetics 163:735-746. 
McDowell, J. M., and Simon, S. A. 2006. Recent insights into $R$ gene evolution. Mol. Plant Pathol. 7:437-448.

Micheletto, S., Boland, R., and Huarte, M. 2000. Argentinian wild diploid Solanum species as sources of quantitative late blight resistance. Theor. Appl.Genet. 101:902-906.

Milligan, S. B., Bodeau, J., Yaghoobi, J., Kaloshian, I., Zabel, P., and Williamson, V. M. 1998. The root knot nematode resistance gene $M i$ from tomato is a member of the leucine zipper, nucleotide binding, leucine-rich repeat family of plant genes. Plant Cell 10:1307-1319.

Niederhauser, J. S., and Mills, W. R. 1953. Resistance of Solanum species to Phytophthora infestans in Mexico. Phytopathology 43:456-457.

Oh, S.-K., Young, C., Lee, M., Oliva, R., Bozkurt, T. O., Cano, L. M., Win, J., Bos, J. I. B., Liu, H.-Y., van Damme, M., Morgan, W., Choi, D., Van der Vossen, E. A. G., Vleeshouwers, V. G. A. A., and Kamoun, S. 2009. In planta expression screens of Phytophthora infestans RXLR effectors reveal diverse phenotypes, including activation of the Solanum bulbocastanum disease resistance protein Rpi-blb2. Plant Cell 21:2928-2947.

Oosumi, T., Rockhold, D., Maccree, M., Deahl, K., McCue, K., and Belknap, W. 2009. Gene Rpi-bt1 from Solanum bulbocastanum confers resistance to late blight in transgenic potatoes. Am. J. .Potato Res. 86:456-465.

Park, T. H., Gros, J., Sikkema, A., Vleeshouwers, V. G. A. A., Muskens, M., Allefs, S., Jacobsen, E., Visser, R. G. F., and van der Vossen, E. A. G. 2005. The late blight resistance locus Rpi-blb3 from Solanum bulbocastanum belongs to a major late blight $R$ gene cluster on chromosome 4 of potato. Mol. Plant-Microbe Interact. 18:722-729.

Pendinen, G., Gavrilenko, T., Jiang, J. M., and Spooner, D. M. 2008. Allopolyploid speciation of the Mexican tetraploid potato species Solanum stoloniferum and $S$. hjertingii revealed by genomic in situ hybridization. Genome 51:714-720.

Rodriguez, A., and Spooner, D. M. 1997. Chloroplast DNA analysis of Solanum bulbocastanum and S. cardiophyllum, and evidence for the distinctiveness of $S$. cardiophyllum subsp. ehrenbergii (sect. Petota). Syst. Bot. 22:31-43.

Ronald, P. C., Salmeron, J. M., Carland, F. M., and Staskawicz, B. J. 1992 The cloned avirulence gene Avrpto induces disease resistance in tomato cultivars containing the Pto resistance gene. J. Bacteriol. 174:1604 1611.

Rose, L. E., Bittner-Eddy, P. D., Langley, C. H., Holub, E. B., Michelmore, R. W., and Beynon, J. L. 2004. The maintenance of extreme amino acid diversity at the disease resistance gene, RPP13, in Arabidopsis thaliana. Genetics 166:1517-1527.

Sandbrink, J. M., Colon, L. T., Wolters, P. J. C. C., and Stiekema, W. J. 2000. Two related genotypes of Solanum microdontum carry different segregating alleles for field resistance to Phytophthora infestans. Mol. Breed. 6:215-225

Song, J., Bradeen, J. M., Naess, S. K., Raasch, J. A., Wielgus, S. M. Haberlach, G. T., Liu, J., Kuang, H., Austin-Phillips, S., Buell, C. R. Helgeson, J. P., and Jiang, J. 2003. Gene RB cloned from Solanum bulbocastanum confers broad spectrum resistance to potato late blight. Proc. Nat.Acad. Sci. U.S.A. 100:9128-9133.

Spooner, D. M., van den Berg, R. G., Rodrigues, A., Bamberg, J. B., Hijmans, R. J., and Lara-Cabrera, S. I. 2004. Wild Potatoes (Solanum section Petota; Solanaceae) of North and Central America. American Society of Plant Taxonomy. Ann Arbor, MI, U.S.A.

Spooner, D. M., Jansky, S. H., and Simon, R. 2009. Tests of taxonomic and biogeographic predictivity: Resistance to disease and insect pests in wild relatives of cultivated potato. Crop Sci. 49:1367-1376.

Stahl, E. A., Dwyer, G., Mauricio, R., Kreitman, M., and Bergelson, J. 1999. Dynamics of disease resistance polymorphism at the Rpm1 locus of Arabidopsis. Nature 400:667-671.

Tan, M. Y. A., Hutten, R. C. B., Celis, C., Park, T. H., Niks, R. E., Visser, R. G. F., and van Eck, H. J. 2008. The Rpi-mcd1 locus from Solanum microdontum involved in resistance to Phytophthora infestans, causing a delay in infection, maps on potato chromosome 4 in a cluster of NBSLRR genes. Mol.Plant-Microbe Interact. 21:909-918.

Tian, D., Traw, M. B., Chen, J. Q., Kreitman, M., and Bergelson, J. 2003. Fitness costs of $R$-gene-mediated resistance in Arabidopsis thaliana. Nature 423:74-77.

van der Vossen, E. A. G., Sikkema, A., te Lintel Hekkert, B., Gros, J. Stevens, P., Muskens, M., Wouters, D., Pereira, A., Stiekema, W., and Allefs, S. 2003. An ancient $R$ gene from the wild potato species Solanum bulbocastanum confers broad-spectrum resistance to Phytophthora infestans in cultivated potato and tomato. Plant J. 36:867-882.

van der Vossen, E. A. G., Gros, J., Sikkema, A., Muskens, M., Wouters, D., Wolters, P., Pereira, A., and Allefs, S. 2005. The Rpi-blb2 gene from Solanum bulbocastanum is an $\mathrm{Mi}-1$ gene homolog conferring broadspectrum late blight resistance in potato. Plant J. 44:208-222.

Van Poppel, P., Jiang, R., J. Sliwka, A., and Francine Gover, S. 2009. Recognition of Phytophthora infestans Avr4 by potato R4 is triggered by Cterminal domains comprising W motifs. Mol. Plant Pathol. 10:611-620.

van Poppel, P. M. J. A., Guo, J., van de Vondervoort, P. J. I., Jung, M. W. M., Birch, P. R. J., Whisson, S. C., and Govers, F. 2008. The Phytophthora infestans avirulence gene Avr4 encodes an RXLR-dEER effector. Mol. Plant-Microbe Interact. 21:1460-1470.

Vleeshouwers, V. G. A. A., and Rietman, H. 2009. In planta expression systems. Pages 455-475 in: Oomycete Genetics and Genomics. K. H Lamour and S. Kamoun, eds. John Wiley \& Sons, Hoboken, NJ, U.S.A.

Vleeshouwers, V. G. A. A., van Dooijeweert, W., Paul Keizer, L. C., Sijpkes, L., Govers, F., and Colon, L. T. 1999. A laboratory assay for Phytophthora infestans resistance in various Solanum species reflects the field situation. Eur. J. Plant Pathol. 105:241-250.

Vleeshouwers, V. G. A. A., Rietman, H., Krenek, P., Champouret, N., Young, C., Oh, S. K., Wang, M., Bouwmeester, K., Vosman, B., Visser, R. G. F., Jacobsen, E., Govers, F., Kamoun, S., and Van der Vossen, E. A. G. 2008. Effector genomics accelerates discovery and functional profiling of potato disease resistance and Phytophthora infestans avirulence genes. PLoS ONE 3:e2875.

Wang, M., Allefs, S., van den Berg, R. G., Vleeshouwers, V. G. A. A., van der Vossen, E. A. G., and Vosman, B. 2008. Allele mining in Solanum: Conserved homologues of Rpi-blb1 are identified in Solanum stoloniferum. Theor. Appl. Genet. 116:933-943

Yahiaoui, N., Brunner, S., and Keller, B. 2006. Rapid generation of new powdery mildew resistance genes after wheat domestication. Plant J. 47:85-98

Yahiaoui, N., Kaur, N., and Keller, B. 2009. Independent evolution of functional Pm3 resistance genes in wild tetraploid wheat and domesticated bread wheat. Plant J. 57:846-856.

\section{AUTHOR-RECOMMENDED INTERNET RESOURCES}

The Centre for Genetic Resources, the Netherlands (CGN) website: www.cgn.wur.nl 